\title{
Aggressive Behaviors of Sri Lankan Preschool Children: A Mixed Method Study
}

\author{
Buddhiprabha D D Pathirana ${ }^{1}$.
}

\section{ABSTRACT}

Very few studies have explored young children's aggressive behaviors in collective cultures or in South Asian contexts. The present study reconnoitres in depth; the nature, types, prevalence and antecedents of aggressive behaviors displayed by Sri Lankan preschool children. The study was carried out in two phases using a mixed method; 1 . Preschool teacher interviews $(\mathrm{N}=23)$ with teachers from 14 varied preschool contexts in Sri Lanka, and 2. Observations of aggressive behaviors of 16 preschool children displaying prominent overt, and relational aggression from four varied preschool communities selected from a group of 135 children. Findings of this study make important contributions to aggressive behaviors within Sri Lankan preschool children and discuss them in the back drop of global research findings. Findings also provide new information regarding the manner in which aggression was expressed by the observed group of preschool children, labeled as 'playful aggressive parodies' by the author.

Keywords: Aggressive behaviors, preschool children, Interviews, Observations, Sri Lanka

Childhood aggression has been described in terms of direct observable features (Dodge, Coie, \& Lynam, 2006; Ostrov, Woods, Jansen, Casas, \& Crick, 2004; McEvoy, Estrem, Rodriguez, \& Olson, 2003; Crick and Dodge, 1996), antecedents, consequences (White, Moffitt, Earls, Robins, \& Silva, 1990, age (Ostrov, Crick \& Stauffacher, 2006; Kuppens, Grietens, Onghena, Michiels, \& Subramanian, 2008) and aversion to the victim (Coyne, Archer, \& Eslea, 2006). Therefore, childhood aggression could be viewed as a phenomena, which involves forces that are internal to the child (gender, temperament, biological development, self-regulatory processes and social cognitive information processing), forces that are external but within child's social interactions and relationships (Parenting styles, attachment relationships, and peer interactions), and forces that are external and embedded in wide macro structures such as media, community and political violence.

\footnotetext{
${ }^{1}$ Senior Lecturer in Psychology, Department of Philosophy \& Psychology, University of Peradeniya, Sri Lanka *Responding Author

(C) 2016 I B Pathirana; licensee IJIP. This is an Open Access Research distributed under the terms of the Creative Commons Attribution License (http://creativecommons.org/licenses/by/2.0), which permits unrestricted use, distribution, and reproduction in any Medium, provided the original work is properly cited.
} 


\section{Aggressive Behaviors of Sri Lankan Preschool Children: A Mixed Method Study}

Research on childhood aggression also records that aggressive behaviors are common phenomena in the preschool class (Goldstein, Arnold, Rosenberg, Stowe, \& Oritz, 2001), aggressive children are not isolated but are members of networks of similarly aggressive peers (Pepler\& Craig, 1995; Farver, 1996) and children engage in different types of aggressive behaviors such as direct physical (Dodge, Coie, \& Lynam, 2006; Huesmann, Eron, Kefkowitz, \& Walder, 1984; Phillips \& Lochman, 2003; Dodge, 1980), verbal/ relational (Siegler, Deloache \& Eisenbeg, 2003; Crick, Casas \& Ku, 1999; Crick, Casas \& Mosher, 1997) and indirectverbal/relational aggression (Tapper \& Boulton, 2004). Studies on aggression and preschool children also conveys that children are more likely to aggress if another child/children had just performed an act of aggression than if no aggression had occurred (Goldstein, Arnold, Rosenberg, Stowe, \& Oritz, 2001).

Apart from being listed as extremely challenging for teachers' (Snell, Berlin, Voorhees, StantonChapman \& Hadden, 2012), parents', and distressing to peers, aggressive behaviors can also be destructive and harmful to the child concerned (Gilliam, 2004). Moreover, research conveys that aggression is a moderately stable phenomenon throughout the years of childhood (Farrington, 1991), and highly aggressive behaviour often co-occurs with, and is predictive of, (1) poor academic performance and increased risks for dropping out of school (DeRosier, Kupersmidt, \& Patterson, 1993); (2) being seen by teachers and peers as disruptive (Ollendick, Weist, Borden, \& Greene, 1992; Wentzel \& Asher, 1995); and may serve as (3) precursors of delinquent activities (Kupersmidt \& Coie, 1990; Shores \& Wehby, 1999).

On the other hand, research also conveys that positively perceived relationships between childteacher interactions contribute to social competence and less aggression in children while higher levels of aggression were related to negatively perceived child-teacher relationships (Blankemeyer, Flannery, \& Vazsonyi, 2002).

Hence, there are several advantages of considering preschool teacher perceptions of aggression as they influence the discipline related attributions in the preschool class, affect the aggressive children's self-perceptions as well as other children's perceptions of the aggressive children (Chang, 2000). Finally, preschool teacher knowledge and beliefs concerning behavior problems in a preschool classroom if effectively used can perform a vital role in early warning systems of aggression (Bibou-Nankou, Kiosseoglou, \& Stogiannidou, 2000).

Though preschool children's aggressive behavors have been explored extensively across the globe little is known about the possible antecedents, type and nature of childhood aggressive behaviours in Sri Lankan preschool children, or their teacher perceptions of it. Though several recent studies seem to have addressed concepts related to childhood aggression in Sri Lanka such as externalizing (Samarakkody, Fernando, McClure, Perera, \& De Silva, 2012) and disruptive behaviors (Senaratna, 2012) of young children, there seems to be vacuum when it comes to the 


\section{Aggressive Behaviors of Sri Lankan Preschool Children: A Mixed Method Study}

aggressive behaviors in Sri Lankan preschool children. When considering the challenges that Sri Lankan preschools experience such as large number of children per class room, in adequate preschool teacher training pertaining to early violence prevention (Pathirana, 2006) and absence of a structured monitoring mechanism of early childhood care, there seem to be an urgency to explore the nature and types of aggressive behaviors displayed by Sri Lankan preschool children.

\section{METHOD}

The study was carried out in two phases. The phase I comprised of preschool teacher interviews ( $\mathrm{N}=23$ ) to find out the nature and prevalence of aggressive behaviors of the preschool children as perceived by a sample which represents Sri Lankan preschool teachers, Phase II of the study comprised of observations of the aggressive behaviors of 16 preschool children from four different preschool communities in Colombo.

Phase I - During this phase data was collected using a semi structured, open interview schedule which allowed free expression of the respondents' views on the topic, with a duration of 90 to 30 minutes. The interviews took place in offices, classrooms and preschool teacher training centres. The author conducted the interviews preserving the confidentiality of the participants during all stages. Before initiating the interview permission was obtained to tape record the interviews, which were transcribed by the author.

After consulting experts on early childhood education and research methodology a diverse list of participants were compiled, comprising of preschool teachers (18 to 60 yrs) from different contexts such as preschool in the plantation sector, rural \& urban preschools, Sinhala, English and Tamil medium preschools, model preschools funded by the government/ non- governmental organizations, private/ fee levying preschools, preschools of which disabled children were the predominant population, preschool in a street children community, a preschool in a fishing community, preschools in areas of which garment factory workers, security officers \& migrant mothers to the middle-east are the predominant population.

Phase II-During phase II of the study an observation schedule was used. The participants for this phase was selected out of 135(66 boys and 69 girls) preschool children using, culturally adapted Sinhalese Version of Preschool Social Behavior Scale - Teacher Form's (PSBS - T$\mathrm{SV}$ ). The children were attending four varied preschool communities (government, private and, two run by nongovernmental organizations), and were 25 to 72 months of age ( $M=49.5$ months; $\mathrm{SD}=8.011$ ). In the preschools observed, the teacher often worked as the only individual in a moderately large class (Teacher child ration, 1: 30); and children participated in adult initiated, structured, and directed activities for relatively long periods. A period of three months was assigned for this task.

Based on the preschool teacher ratings of the PSBS - T- SV; 16 preschool children (Girls = 07; Boys $=09$ ) selected out of the initial group of 135 preschool children, representing the four preschool communities, displaying the most prominent patterns of overt and relational aggression. 


\section{Aggressive Behaviors of Sri Lankan Preschool Children: A Mixed Method Study}

\section{Instruments}

Open ended interview questionnaire - Preschool Teachers - Preschool teacher perceptions on types, nature, prevalence and antecedents of child aggressive and prosocial behaviors were gathered using a semi-structured interview questionnaire. The questionnaire allowed the participants to reconstruct his or her experience pertaining to aggressive and prosocial behaviors of the preschool children. In this study, aggressive behaviors of the preschool children would be discussed.

To ensure integrity and trustworthiness, all the interview questions were piloted by a panel of resource persons, whose expertise lies in the areas of early childhood education, research methodology, and social psychology. Based on the suggestions of the experts, revisions were carried out. Before conducting the actual interview, a pilot study was conducted to test the interview design with 05 participants. Questions were re-worded or eliminated based on participant feedback. During the pilot phase if it was noticed that certain questions were irrelevant or offensive to the participants, those questions were also eliminated from the questionnaire after consulting the experts. The author interviewed all 23 participants (all females) preserving their confidentiality during all stages of the interviews.

Preschool Social Behavior Scale- Teacher Form, Sinhalese Version (PSBS -T, SV) To identify children with prominent aggressive and prosocial behavioral patterns, culturally adapted version of the Preschool Social Behavior Scale- Teacher Form (PSBS - T) developed by Crick and Mosher (Crick et al., 1997; Crick et al., 1999) was used. This scale was adapted from a previous teacher rating scale constructed by Crick, Casas and Mosher (1987). The initial PSBSTS is a questionnaire comprising of 25 items with six index scores which can be computed for several areas of a preschool child's functioning, including scales: $(1)$ relational aggression $(\mathrm{n}=$ 08), (2) overt/physical aggression ( $n=08)$, (3) prosocial behaviour ( $n=04)$, (4) depressed affect ( $\mathrm{n}=03)$, (5) Child's acceptance with same sex peers $(\mathrm{n}=01)$ and (6) child's acceptance with opposite sex peers $(n=01)$. Teachers rated each child on a five point scale from 1 (never or almost never true) to 05 (always almost true). PSBS -T-SV was used to identify children with prominent prosocial and aggressive behavior patterns. This is a standardized instrument, validated on 129 children in preschools located in a moderately sized Midwestern town in Minnesota. Permission to use the scale was obtained from the authors (Crick's lab in Minnesota, USA).

For this study, culturally adapted version of the Preschool Social Behavior Scale - Teacher Form was used and thus be called Preschool Social Behavior Scale - Teacher Form - Sinhalese Version (PSBS - T- SV), using Delphi Technique (Pathirana, 2006).In this study, the Delphi process was carried out in two rounds. In the first round, the scale was given to 7 experts whose expertise was in the fields of early childhood education, clinical and child psychology. They were requested to rate each question from 0 to 9 , with 0 indicating the lowest level of each characteristic and 9 indicating the highest on three aspects; a) cultural relevance, b) retaining the conceptual meaning and c) its content suitability to be used with the sample (preschool teachers). 


\section{Aggressive Behaviors of Sri Lankan Preschool Children: A Mixed Method Study}

The experts were also requested to rate the suitability of the PSBS-T's sub scales: relational aggression, overt aggression, depressed affect, prosocial behavior, child's acceptance with same sex peers and child's acceptance with opposite sex peers, using a scale of 0 to 9 . The ratings of the experts' scales were collected and averaged. In the second round, six experts who participated in the first round were requested to re-rate their previous rating based on the first round average. Next, the re-rating on the second round was also averaged. If a question was rated higher than 3 by all the experts it was retained. Since the scores for each question yielded a score of more than 3 , all questions were selected to be included in the study in addition to 05 questions suggested by the experts. The final version of the PSBS - T-SV comprised of 30 questions. The preschool teachers were requested to rate frequency of the behaviors of the children on a 5-point scale ( 1 = never or almost never true, $5=$ always or almost true) in response to these 30 statements such as, "This child is good at sharing and taking turns" or "This child kicks or hits others". Preschool teachers were provided with written and verbal instructions on scoring of the scale and the author was available to ask questions if they required clarifications.

\section{Observations}

All observations were conducted using a pre-designed observation schedule by the author. Average time observed per child was 40 minutes. Six to six observation sessions, on three different days per child were carried out across five different activities: while children observed their religion in the morning, structured activity in the class room, two unstructured activities in the class (while eating/ before school), two unstructured activities outside the classroom (free play/ after school). The children were observed on a rotation sequence to ensure that all three children in each preschool class were observed on a regular basis, during which relational, physical aggressive acts as well as prosocial acts were recorded. Prior to the observation, the author introduced herself to the teachers and spent minimum of two days in the classroom to habituate children to this process. At the end of observation sessions, discussions were held with the preschool teachers pertaining to the observed behaviors of the children.

Observational Schedule - The highest scorers of relational, physical and prosocial behaviour from each preschool for the PSBS - T, SV were observed by the author. She used direct observations method to observe each of these behaviours and their interrelates (child/ teacher responses to these behaviors). The frequency of these behaviors was scored based on definitions used by Crick and colleagues (1997).

i. Relational aggression - Verbal or nonverbal behavior that harms others through damage to their peer relationships (such as excluding others from play or encouraging others to exclude a peer from play).

ii. Physical/ overt aggression - Behaviors that harm others through physical damage or threats of such damage (eg. pushing, hitting, kicking, or threatening to beat up a peer)

iii. Teacher practices - responses or reactions of the preschool teachers to observed aggressive or prosocial acts of the selected child. 


\section{Aggressive Behaviors of Sri Lankan Preschool Children: A Mixed Method Study}

In order to avoid the disturbance effect of multiple observers, the author, who had established a good rapport with the children and teachers before starting the study, made all the observations. The protocol of the semi-structured observation contained tables to record aggressive and prosocial behavioral patterns observed in children during activity sessions, as well as preschool teacher responses pertaining to those behavioral patterns. They were tabulated in the following format:

a. Antecedent - Included the location and the events that preceded the aggressive/ prosocial behavior of the child

b. Behavior - Included descriptions of children's aggression/ prosocial behavior

c. Consequences -Included any immediate results such as the responses of the teachers, peers, material gains and losses that followed the aggressive/ prosocial behavior

\section{RESULTS}

Phase I - Preschool Teacher Interviews - The research enquiry, preschool teacher perceptions pertaining to aggressive behaviors of preschool children surfaced several interesting findings. Preschool teachers reported instances of physical/ overt aggressive behaviors (e.g. pinching, hitting, throwing things at others, kicking, )hitting the teacher when they are extremely angry, destroying art and craft work of peers and art/craft displayed in the preschool class as well as sophisticated relational/ verbal (e.g. crying, scolding, ignoring)aggressive behaviors.

Most frequently reported physical/ overt aggressive acts were pushing, shoving other children when going in a queue $(n=20)$, pinching $(n=23)$, hitting $(n=23)$, throwing things at others $(n=$ 23), grabbing toys/art/craft of peers $(n=23)$, hitting the teacher when they are extremely angry $(n=05)$, destroying art and craft work of peers and art/craft displayed in the preschool class $(n=$ 23). Moreover, preschool teachers, also perceived that fights frequently occurred when several children wanted to play with the most popular toy/s in the preschools $(\mathrm{n}=23)$. Most frequently reported relational/verbal aggressive acts were, name calling $(n=23)$, scolding $(n=23)$, taunting, and social exclusion (e.g. refusing to allow peers included when playing house...) and using socially undesirable words [('Kunuharupa') $(\mathrm{n}=05)]$.

Children in my preschool use very bad words (meaning socially undesirable words which are not spoken in the public), words which I cannot even tell anyone when they think I am not paying attention to them. They learn them from the neighbourhood as well as from their parents. (Preschool teacher from a street children community).

Majority of the teachers $(n=20)$, reported that the intensity of the aggression varied among children in their preschools. Majority of the children were described to be 'well behaved' to displaying moderate aggressive behaviors; with few children (perceived to be one or two) displaying extreme persistent aggressive behavioural patterns. The instances of aggressive behaviors of these children (displaying extreme persistent aggressive acts); as quoted by the preschool teachers were throttling, twisting the hands of peers, and thrashing other children 


\section{Aggressive Behaviors of Sri Lankan Preschool Children: A Mixed Method Study}

resulting bleeding/wounding. A significant number of preschool teachers $(n=15)$ also mentioned that they feel relieved on the days that 'these children' did not attend the preschool.

Preschool teachers $(n=23)$ also perceived that girls display more relational/verbal aggression while boys display more physical/ overt aggression. Large number of teachers also mentioned that if there were more boys in the class in a particular year, they would require additional help (i.e enlist the help of parents, get paid help) to manage the class, as there would be frequent episodes of overt/ physical aggressive acts.

Even though the general consensus of the interviewees was that girls are more helpful, several teachers stated instances of girls displaying verbal aggression. One preschool teacher recalled an instance when a girl displayed a fairly complicated form of relational aggression.

There is a girl in my class who always tells other children that she is either friendly or angry with them (indicating with the thumb the way she does it, thumbs up or down). One day all the children in the preschool were watching television. When children watch television they sit together in cliques, three children here... four children there... like that... This girl went to one clique and told them that she is friendly with them, showing the thumbs up sign, then went to another clique and told them that she's angry with them, with the thumbs down sign. This action made children in that group very irritated and angry; they too told her that they are angry with her. She went to yet another group; I think to seek help, because she told them 'Hello, they (indicating the group of children) are saying they are angry with me'. Those children ignored her. However, her second attempt was successful. To make things short, somehow she managed to persuade children in that group to come and fight with the children who said that they are angry with her. I was silently watching all this.

Significant number of teachers $(n=14)$ seemed to have perceived aggressive behaviors are more prevalent among children when they first come to school and gradually diminishes after the first two/three months. The types of acts reported were fighting for toys, swings and other play equipment in the playground, rolling on the floor, hitting, scratching other children. Teachers also mentioned that children did not like to sit inside the class, refuse to go in a queue to wash hands, wanted to own all the toys and did not share things with others during the first few weeks/months. Teachers perceived that only child in the family or children without playmates displayed relatively more aggressive behaviors desiring exclusive teacher attention and toys when they first come to the preschool. They attributed it to the absence of play opportunities with peers.

There is a child who used to pinch, hit and harass other children when he first came to the preschool. It has been five or six months since he first came to the preschool...though he still hits and harasses others I feel his aggressive behavior has decreased over time. It is really less 


\section{Aggressive Behaviors of Sri Lankan Preschool Children: A Mixed Method Study}

compared to the things he used to do. I think it could be due to the fact he gets the opportunity to stay with other small children. He is the only child. The parents are working, he is looked after by an aunt or grandmother.

Children's limited attention span was also attributed as a cause of aggression. Teacher interviews conveyed that short attention span of the preschool children leading to boredom impacted physical/relational aggression. Teachers also reported that children shout, scream, 'silently pinch the child next him/her', or hurt other children. Therefore, preschool teachers felt that activities carried out in the preschool should be of short to suit the attention span of the children. They also reported that children feel restless when they are forced to engage in frequent, routine and mundane activities or forced to stay inside the class for relatively long periods.

The type of community that children live in was also attributed as a cause contributing to the aggressive behaviors of the children. For instance, preschool teachers who teach children coming from violent frequent neighborhoods witnessing frequent fights among neighbors (e.g. children from street families, fishing communities, children whose parents were employed as plantation workers) described them to be more aggressive. Teachers perceived this to be due to be several reasons, 1. irritability/ impatience experienced by the child of being confined to the house by the caregivers due to occurrences of violence in their neighborhood; 2. Being exposed to orcoviewing of violent cartoons, Tamil \& Hindi films; and 3.Frustration experienced due to inadequate play opportunities with peers.

Factors associated with type and quality of parenting was also reported to be concomitant with aggressive behaviors of the preschool children. Children who came from homes with strict/ rigid disciplinary structures with authoritarian caregivers often using physical abuse and/or corporal punishment or verbal abuse as a form of discipline (e.g. scolding, using undesirable words)were perceived to be comparatively more aggressive than children whose parents were authoritative and used positive discipline.

A child in my preschool destroys beautiful things in the classroom, hits other children, pinches and harasses girls in the class. His parents hit him and scolds him for everything, I think this is due to it.

Absence of parents [e.g. having a mother working as migrant workers in Middle East $(\mathrm{n}=05)$ and a father in prison $(\mathrm{n}=01)$ ] was also recognized to causes and escalates of aggression within preschool children by the teachers. Teachers also perceived factors such as inadequate parental supervision, domestic violence, and parental (mostly paternal) alcoholism, watching/co-viewing violent television programs as instigators and escalators of aggression within preschool children. For example, when referring to a child whose parents are visually impaired, a preschool teacher said that 'he does not heed what the parents say and is constantly running to a nearby house to 
watch television, from which he has learnt to imitate aggressive behaviors'. Similarly, teachers reported that children who witnessed domestic violence and/ or parental (mainly paternal) abuse of alcohol, had mothers who worked as migrant workers in the Middle East were withdrawn, fearful, preferred to play by themselves and were extremely aggressive in the preschool, either harassing and/or destroying belongings of their peers, in comparison to children who did not experience these difficult circumstances.

Television was also named as an instigator, precursor and antecedent of aggression within children by a large majority of the participants $(n=21)$, while none cited its positive impacts. Preschool teachers were quick to refer to negative impacts of television such as imitation of relational/physical aggressive acts (i.e. shooting, hitting or using undesirable words). Preschool teachers also reported that children who co-viewed violent television programs or videos with their parents (especially fathers)/ care givers displayed more physical/ overt aggressive behaviors than others.

\section{Results - Phase II - Observation of Aggressive Behaviors of Preschool Children in Four}

Selected Preschools - Based on the PSBS-T-SV scores, means and standard deviations for each behavior (RA and OA) were calculated. A positive relationship was observed between overt and relational aggression $(\mathrm{r}=.81$ ) while significant relationship between relational aggression and prosocial behaviour $(\mathrm{r}=.01)$ and overt aggression and prosocial behaviour were not observed ( $\mathrm{r}$ $=-.248)$.

Though there was only a marginal difference between boys and girls, more boys $(\mathrm{n}=06)$ than girls $(\mathrm{n}=03)$ displayed forms of overt aggression while more girls $(\mathrm{n}=04)$ than boys $(\mathrm{n}=$ 03)displayed acts of relational aggression.

Instances of overt aggression observed were pushing/shoving, pinching, biting, kicking, spitting, grabbing toys/ books from peers, running away with toys belonging to other children, breaking art/ craft projects and grabbing and running toys/ craft of peers. It was also noted, that the boys in the observed group, with high scores of aggression often initiated fights and fought with their peers.

Instances of relational aggression observed were complaining to the teacher misbehaviors of other children, telling other children that "I am no longer your friend", indicating thumbs down sign to peers to convey that 'I am angry with you/ mad at you or I am not your friend anymore', (Observed to create distress within the victim), frowning, scowling at other children or as well as threatening peers that they will give 'toku' (hitting the head with knuckles of the hand). Relative to overt aggression extremely few episodes of relational aggression were observed. Girls as well as boys were observed to be displaying acts of relational aggression. The outcomes of relational aggressive episodes were relatively analogous to those outcomes observed in overt aggression 


\section{Aggressive Behaviors of Sri Lankan Preschool Children: A Mixed Method Study}

(i.e. the victim appeared to be distressed, cried and left the situation or complained to the teacher that 'he/she is mad/ angry at me').

Also observed were behaviors which could be categorized as "playful aggressive" acts or parodies. Instances of playful aggression included pretending to shoot at other children with guns made of play blocks, playing hit and run games, turn taking in hitting and hurting (e.g. in a dyad, one child who was hit pretended to get hurt, then hit the other child and he/she pretended to get hurt himself/herself, one child pretending to be an animal, crawling on the floor and pretending to bite other children, hit other children).

Moreover, when children displaying prominent aggressive behavioral patterns interacted with children of similar behavioral patterns the probability occurrence of aggressive acts were comparatively higher than when a child with prominent aggressive behavior pattern interacted with a child displaying a prominent prosocial or non-aggressive behavioral pattern. If a child with a prominent aggressive behavior pattern hit a child with a moderate or prominent prosocial behavioral pattern it was observed that prosocial children displayed a propensity to ignore it as an accident in the first instance or used words to express their dislike such as "Why did you hit me?”, "Do not hit me I do not like it!” or walk away from the aggressor. Hence, during such interactions fights or conflicts were less frequent.

\section{DISCUSSION}

Phase I - Preschool Teacher Interviews - The purpose of the interview phase was to explore the nature and types of aggressive behaviors perceived by preschool teachers from varied preschool communities. Findings from the teacher interviews conveyed that children displayed overt/ physical (Dodge, 1980; Dodge \& Newman,1981)as well as verbal/relational aggression (Crick et al., 1997). Hence, findings of the research convey that relational/verbal as well as overt aggression maybe a universal phenomenon, even though there maybe cultural variation in which it is expressed. Moreover, the findings also came up with an instance of a complicated form of relational aggression, similar to that described by Ostrov, Woods, Jansen, Casas, and Crick (2004) in their article title “This white crayon doesn't work...”.

The preschool teachers attributed causes of aggression to varied reasons such as: 1. individual (e.g. being the only child in the family) 2. Factors associated with type and quality of parenting provided to children (e.g. inadequate parental supervision, absence of mothers/ fathers, excessive use of corporal punishment/verbal abuse) and 3. Being subjected to domestic, community and television violence; was in par with the previous research findings (Levendosky, Huth-Bocks, Shapiro, \& Semel, 2003; Anderson, Huston, Schmitt, Linebarge, \& Wright, 2001) carried out in the Euro-American contexts.

The findings of present research were also congruent with the literature which suggests that there is a strong association between alcohol and domestic violence (McMurran, 1999). Researchers speculate that exposure to domestic violence has particularly adverse effects on preschool children because they are at the stage of developing a sense of trust, security and attachment (Levendosky, Huth-Bocks, Shapiro, \&Semel, 2003; DeMulder, Denham, Schmidt, \& Mitchell, 2000,; Raver \& Knitzer, 2002) and do not possess sophisticated language and cognitive skills to discuss and deal with traumatic events.

(C) The International Journal of Indian Psychology, ISSN 2348-5396 (e)| ISSN: 2349-3429 (p) | 75 


\section{Aggressive Behaviors of Sri Lankan Preschool Children: A Mixed Method Study}

Direct and indirect impact of community (Farver et al., 1999; Farver et al., 2005) and television (Garbarino et al., 1991) violence, also records similarities with those carried out in the EuroAmerican contexts. Research also conveys that parental co-viewing preferences, habits, and orientations toward television influence children's viewing, both with and without parents (St. Peters, Fitch, Huston, Wright, and Eakins, 1991), and co-viewing of controversial content without making comments sometimes may communicate tacit approval of the behavior witnessed, thereby enhancing the effect of such content (Slaby, Roedell, Arezzo, \& Hendrix, 1995).

Strength of this phase of the study lies in its method of data collection; semi-structured interview guide used to collect a data from a diverse group of preschool teachers representing varied ethnic, geographical, socio-economical, teacher qualification and experiences in Sri Lanka. Outcome of the interviews provided rich descriptions and in depth information of preschool teacher perceptions pertaining to nature, type, prevalence, and antecedents of aggressive behaviors within Sri Lankan preschool children, which afforded the opportunity to examine similarities, differences, and distinctiveness in the gathered data against the back drop of global research findings (Crick et al, 1997; Coie et al, 1983; Dodge, 1980).

Although this section of the study presents significant findings on Sri Lankan preschool teacher perceptions, practices, attitudes and needs pertaining to aggressive behaviors in preschool children, all data for this section was generated using teachers' self-reports. Even though selfreports are in a unique position to report on internal views especially regarding the practices, beliefs, attitudes and needs (Raviv et al., 2001); there are questions about the validity and reliability of teacher perceptions as teachers may over identify the behaviors of the children (Stipek et al., 1997; McEvoy, 2003). Therefore, caution should be exercised in interpreting the findings reported, on children's aggressive behaviors.

Phase II - Observation of Aggressive Behaviors of Preschool Children in Four Elected Preschools - The purpose of this study was to observe the nature and types of aggressive behaviors of the Sri Lankan preschool children. In order achieve this objective all children ( $\mathrm{n}=$ 135)from four selected preschools in Colombo district (Capital of Sri Lanka) were assessed for their relational aggression, over aggression and prosocial behaviour using PSBS - T- SV. Based on the scores, 16 children who scored high on relational and overt aggression were observed.

Based on the findings of the observations following interpretations were made. First, the overall findings do not indicate significant differences by gender for relational and overt aggression. This was a finding incongruent with the previous literature and research (Siegler et al, 2003; McEvoyet al., 2003; Cricket al, 1999; Cricket al, 1997; Ostrov et al, 2004). However, all these studies have been carried out in western contexts. Therefore, future studies need to look into the cultural aspects of relational aggression displayed by Sri Lankan girls and boys.

Second, the nature and types of observed overt aggressive behaviors were congruent with those reported by the preschool teachers during the interviews. Findings also conveyed that one episode of overt aggression was instrumental in creating contagion or chain reactions of aggression in the class, again a finding congruent with the previous research (Goldstein, Arnold, Rosenberg, Stowe, \& Oritz, 2001). 


\section{Aggressive Behaviors of Sri Lankan Preschool Children: A Mixed Method Study}

Third, findings also provided new information regarding the manner in which aggression was expressed by the observed group of preschool children. Each child reacted differently to aggressive behaviors which were labeled as 'playful aggressive parodies' by the author. Examples for these behaviours were standing and crying, attacking the playful aggressor or shouting and running away. The observations revealed while some children (mostly boys in the observed group) seemed to enjoy these acts, others (mostly girls) seemed to be genuinely distressed and fear the child who took the role of the 'playful aggressor'. Some children were dragged into such play- aggression situations (shooting each other, being shot at, and being chased by the child pretending to be an animal) though they did not desire to be so included. However, when included they spontaneously went on with this playful aggressive parody while indicating that they do not want be part of it by conveying their distress in different ways such as crying or protesting. Since preschool children find it difficult to differentiate between reality, pretence and false belief, such playful forms of aggression may also have initiated/ increased or escalated aggressive behaviors within preschool children. Therefore, future researches need to identify whether this 'playful aggressive parody' is a unique form of culturally expressed aggression for Sri Lankan pre/school children. Also, whether children perceive these play aggression parodies to be actual acts of aggression. Moreover, when developing an intervention program, program developers would need to explore the possibility replacing these playful aggressive parodies' with 'playful prosocial behaviour parodies'.

Fourth, the outcomes of relational aggressive episodes were quite similar to those outcomes observed in overt aggression (i.e. the victim appeared to be distressed, cried and left the situation or complained to the teacher that 'he/she is mad/ angry at me') as well as stated in the previous research (Goldstein et al., 2001). However, varied forms of relational aggression listed in the research literature such as not talking to each other, direct social exclusion, spreading rumors about each other, and threatening (Crick et al., 1997), were not observed during this phase. Though this may be attributable to the limited observation time, there is a need to explore whether expressions of relational aggression differs across cultures.

The study being the first of its kind (i.e. direct observation of children's relational and overt aggression in the naturalistic preschool environment across different activities in four preschools with varied backgrounds conducted in the Sri Lankan milieu) contributes unique information pertaining to the aggressive behaviors of Sri Lankan preschool children. However, given the low frequency of aggression in the observation data several limitations in this phase is recorded. First, it was difficult to observe the natural behaviors of the children at a stretch due to various activities such as exhibitions, sports meets, year-end concerts, and holidays. Second, inability to record conversation between and among children due to the non-use of sophisticated technological instruments was a clear constraint especially in recording instances of relational aggression. Hence, future research conducted in Sri Lankan milieu should consider the use of more sophisticated technological devices as the literature reveals that the use of video cameras, microphones, and independent observers in the preschool situation have yielded a wealth of valuable, objective information about relational and overt aggression in young children (Tapper et al., 2002; Pepler et al., 1995).

Aggression which prevails from early childhood onward, and other forms of conduct-regulation difficulties conveys stable phenomena (Cairnset al, 1988; Coie\& Dodge, 1983), been associated 
with and predictive of poor academic performance, disruptive behavior at school, increased risk for school dropout, and engaging in delinquent activities (Coieet al1998), and relatively high prevalence of externalizing behaviors within Sri Lankan preschool children (Samarakkody et al, 2012), an in depth analysis pertaining to aggressive behaviors within Sri Lankan preschool children seem to be a high priority.

Though large number of research studies has been carried out in the Euro-American contexts pertaining to this topic very few studies exist in the South Asia on this area. Hence, this study contributes to the global as well as local research milieu of aggression and preschool children recording similarities with global findings of types, nature, developmental milestones, gender differences, and antecedents on aggressive behaviors of young children. Further, this study also illustrates the significance of investigating socio-cultural ethos pertaining to childhood aggression, in the continuum of meaning making and identifying/ developing plausible interventions.

However, the present study was limited by its sample size on preschool children observed. Therefore, future research need to look closely into the cultural and ethno-political precursors of aggression in Asian contexts with a more diverse and large sample. Moreover, as a country plagued by varied types of violent acts for almost three decades, due to the conflict which prevailed; Sri Lankan children could be more vulnerable to the impact of violence and abuse in comparison to the children growing up in the Euro-American contexts. Also, they may have developed passive aggressive behaviors or acts of aggression different to those displayed by children living in non-violent contexts, which future studies requires to explore.

\section{Acknowledgments}

The author appreciates all those who participated in the study and helped to facilitate the research process.

\section{Conflict of Interests}

The author declared no conflict of interests.

\section{REFERENCES}

Anderson D.R., Huston A.C, Schmitt K.L, Linebarger D.L, \& Wright J.C. (2001). Early childhood television viewing and adolescent behavior: the recon tact study. Monographs of the Society for Research on Child Development, 66(1), I-VIII, 1-147.

Bibou-Nankou.I., Kiosseoglou, G., \& Stogiannidou, A.(2000). Elementary teachers’ perceptions regarding school behavior problems: Implications for school psychological services. Psychology in the Schools, 37, 123 - 134.

Blankemeyer, M., Flannery, D.J., \&Vazsonyi, A.T. (2002).The role of aggression and social competence in children's perceptions of the child-teacher relationship. Psychology in the Schools, 39, $293-304$.

Cairns, R. B., Cairns, B. D., Neckerman, H., Gest, S., \&Gariépy, J.-L. (1988). Social networks and aggressive behavior: Peer support or peer rejection? Developmental Psychology, 24, 815-823. 
Chang, L. (2003). Variable effects of children's aggression, social withdrawal, and prosocial leadership as functions of teacher beliefs and behaviors. Child Development, 74, 535 - 548.

Crick, N.R., Casas, J., \& Mosher, M. (1997). Relational and overt aggression in preschool. Developmental Psychology, 33, 579-588.

Crick, N.R., Casas, J.F., \& Ku, H-C. (1999). Relational and physical forms of peer victimization in preschool. Developmental Psychology, 35, 376-385.

Coie, J. D., \& Dodge, K. A. (1983). Continuities and changes in children's social status: A fiveyear longitudinal study. Merrill-Palmer Quarterly, 29, 261-282.

Coie, J. D., \& Dodge, K. A. (1998). Aggression and antisocial behavior. In W. Damon (Series Ed.) \& N. Eisenberg (Vol. Ed.), Handbook of child psychology: Vol. 3. Social, emotional, and personality development (5th ed., pp. 779-862). New York: Wiley.

Copeland-Mitchell, J., Denham, S. A., \& DeMulder, E. K. (1997). Q-sort assessment of childteacher attachment relationships and social competence in the preschool. Early Education and Development, 8, 27-39.

Coyne, S.M., Archer, J., \&Eslea, M. (2006). “We're Not Friends Anymore! Unlessy”: The Frequency and Harmfulness of Indirect, Relational, and Social Aggression, Aggressive behavior, 32, $294-307$.

Dodge, K. A., Coie, J. D., \&Lynam, D. (2006). Aggression and antisocial behavior in youth. In W. Damon (Ed.), Handbook of Child Psychology (6th edition), N. Eisenberg (Vol. Ed.), Social, Emotional, and Personality Development.

Dodge, K. A. (1980). Social cognition and children's aggressive behavior. Child Development, $51,162-170$.

Dodge, K.A., \& Newman, J. P. (1981). "Biased decision making processes in aggressive boys." Journal of Abnormal Psychology, 90, 375-379.

Dodge, K. A., Pettit, G. A., \& Bates, J. E. (1994). Socialization mediators of the relation between socioeconomic status and child conduct problems. Child Development, 65, 649-665

DeMulder, E.K., Denham, S., Schmidt, M., \& Mitchell. (2000). Q-sort assessment of attachment security during the preschool years: Links from home to school. Developmental Psychology, 36, $274-282$.

DeRosier, M., Kupersmidt, J. B., \& Patterson, C. J. (1993). Children's academic and behavioral adjustment as a function of the chronicity and proximity of peer rejection. Child Development, 65, 1799-1913.

Fallu, J. S., \& Janosz, M. (2001, April). The quality of teacher-student relationships in adolescence: A protective factor of school failure (Poster presented at the biennial meeting of the Society for Research in Child Development, Minneapolis, MN.

Farrington, D. (1991). Longitudinal research strategies: Advantages, problems, and prospects. Journal of the American Academy of Child and Adolescent Psychiatry, 30, 369-374.

Farver, J.A. (1996). Aggressive behavior in preschoolers' social networks: Do birds of a feather flock together? Early Childhood Research Quarterly, 11, 333-350.

Farver, J.A.M., Xu, Y., Eppe, S., Fernandez, A., and Schwartz, D. (2005). Community violence, family conflict, and preschoolers' socio-emotional functioning. Developmental Psychology, 41, 160 - 170.

Garbarino, J., Kostelny, K., \&Dubrow, N. (1991) No place to be a child: Growing up in a war zone. Lexington. M.A: Lexington Books. 


\section{Aggressive Behaviors of Sri Lankan Preschool Children: A Mixed Method Study}

Gilliam,W. (2004). Prekindergarteners left behind: Expulsion rates in state prekindergarten systems. Retrieved on 10th of February, 2013 from http://www.challengingbehavior.org/explore/policy_docs/prek_expulsion.pdf.

Goldstein, N.E., Arnold, D.H., Rosenberg, J.L., Stowe, R.M., \& Oritz, C. (2001).Contagion of aggression in day care classrooms as a function of peer and teacher responses. Journal of Educational Psychology, 93, 708-719.

Hamre, B. K., \& Pianta, R. C. (2001). Early teacher-child relationships and the trajectory of children's school outcomes through eighth grade. Child Development, 72, 625-638.

Huesmann, L.R., Eron, L.D., Kefkowitz, M.M., \& Walder, L.O. (1984).The stability of aggression over time and generations. Developmental Psychology, 20, 1120-1134.

Kupersmidt, J. B., \&Coie, J. D. (1990). Preadolescent peer status, aggression, and school adjustment as predictors of externalizing problems in adolescence. Child Development, 61, 1350-1362.

Kuppens, S., Grietens, H., Onghena, P., Michiels, D, \& Subramanian, S.V. (2008). Individual and classroom variables associated with relational aggression in elementary-school aged children: A multilevel analysis. Journal of School Psychology, 46, 639-660.

Ladd, G. W., \& Burgess, K. B. (2001). Do relational risks and protective factors moderate the linkages between childhood aggression and early psychological and school adjustment? Child Development, 72, 1579-1601.

Levendosky, A. A., Huth-Bocks, A. C., Shapiro, D. L., \& Semel, M. A. (2003). The impact of domestic violence on the maternal -child relationship and preschool-age children's functioning. Journal of Family Psychology, 17, 275-28

McMurran, M. (1999).Alcohol and violence. Child Abuse Review, 8, 219-230.

McEvoy, M.A., Estrem, T.L., Rodriguez, M.C., \& Olson, M.L. (2003). Aggression among preschool children: intermethod agreement available on line at: Retrieved on 9th of February, 2005 from,

http://www.findarticles.com/p/search?qt=disruptive+behavior\%2F+preschool+teacher+p erceptions\&tb=art\&qf=all\&sn=15 .

Ollendick, T. H., Weist, M. D., Borden, M. C., \& Greene, R. W. (1992). Sociometric status and academic, behavioral, and psychological adjustment: A five-year longitudinal study. Journal of Consulting and Clinical Psychology,

Ostrov, J., \& Keating, C. (2004). Gender differences in preschool aggression during free play and structured interactions: An observational study. Social Development, 13, 255-277.

Ostrov, J., Crick, N., \& Stauffacher, K. (2006). Relational aggression in sibling and peer relationships during early childhood. Applied Developmental Psychology, 27, 241-253.

Ostrov, J. M., Woods, K. E., Jansen, E. A., Casas, J. F., \& Crick, N. R. (2004). An observational study of delivered and received aggression, sex and social-psychological adjustment in preschool: “This white crayon doesn't work...”.Early Childhood Research Quarterly, 19, 355-371.

Pathirana, B.D.D. (2006). Doctoral dissertation, “An inquiry into early violence/aggression and prosocial behaviors in preschool children in Sri Lanka to identify appropriate interventions”. University of Colombo, Sri Lanka

Patterson, G. R., Reid, J. B., \&Dishion, T. J. (1992). Antisocial boys. Eugene, OR: Castilia.

Siegler, R., Deloache, J., \& Eisenberg, N. (2003). How children develop. New York: Worth Publishers.

Pepler, D.J., \& Craig, W.M., \& Roberts, W.L. (1998).observations of aggressive and non aggressive children on school playground. Merrill-Palmer Quarterly, 44, 55-76. 
Phillips, N.C., \& Lochman, J.E. (2003).Experimentally manipulated changes in children's proactive and reactive aggressive behavior. Aggressive Behavior, 29, 215 - 227.

Raver, C.C., \& Knitzer, J. (2002).Promoting the emotional well-being of children and families policy paper No. 3 ready to enter: what research tells policy makers about strategies to promote social and emotional school readiness among three-and four-year-old children. Retrieved on 3rd of December, 2005 from http://www.nccp.org/ media/pew02c-text.pdf. Downloaded on 3.12.2005.

Raviv, A., Erel, O., Fox, N.A., Leavitt, L.A., Raviv, A., Dar, I., Shahinfar, A., \& Greenbaum, C.W. (2001).Individual measurement of exposure to everyday violence among elementary school children across various settings. Journal of Community Psychology, $29,117-140$

van Ijzendoorn, M. H., Sagi, A., \& Lambermon, M. W. E. (1992). The multiple caretaker paradox: Data from Holland and Israel. In R. C. Pianta (Ed.), Beyond the parent: The role of other adults in children's lives (pp. 5-24). San Francisco: Jossey-Bass.

Samarakkody, D., D., Fernando, D., McClure, R, Perera., H \& De Silva, H (2012). Prevalence of externalizing behavior problems in Sri Lankan preschool children: birth, childhood, and socio demographic risk factors. Social Psychiatry Epidemiology, 47, 757-762.

Senaratna, B.C.V. (2012). Left-behind children of migrant women: Difficulties encountered and strengths demonstrated. Sri Lanka Journal of Child Health, 41(2), 71-75

Slaby, R.G., Roedell, W.C., Arezzo, D., \& Hendrix, K. (1995).Early violence prevention: tools for teachers of young children. Washington, D.C: National Association for the Education of Young Children.

Snell, M. E., Berlin, R. A., Voorhees, M. D., Stanton-Chapman, T. L., Hadden, S. (2012). A survey of preschool staff concerning problem behavior and its prevention in Head Start classrooms. Journal of Positive Behavior Interventions, 14 (2): 98.

St. Peters, M., Fitch, M., Huston, A. C., Wright, J. C. and Eakins, D. J. (1991), Television and Families: What Do Young Children Watch with Their Parents?. Child Development, 62: 1409-1423. doi: 10.1111/j.1467-8624.1991.tb01614.x

Snell, M. E., Berlin, R. A., Voorhees, M. D., Stanton-Chapman, T. L., Hadden, S. (2012). A survey of preschool staff concerning problem behavior and its prevention in Head Start classrooms. Journal of Positive Behavior Interventions, 14 (2), 98.

Tapper, K., \& Boulton, M. J. (2004).Sex differences in levels of physical, verbal and indirect aggression amongst primary school children and their associations with beliefs about aggression. Aggressive Behavior, 30, 123 - 145.

Wentzel, K. R., \& Asher, s. R. (1995). The academic lives of neglected, rejected, popular, and controversial children. Child Development, 66, 754-763.

White, J., Moffitt, T. E., Earls, F., Robins, L. N. \& Silva, P. A. (1990). How early can we tell? Preschool predictors of boys' conduct disorder and delinquency. Criminology, 28, 507-533.

How to cite this article: B Pathirana (2016), Aggressive Behaviors of Sri Lankan Preschool Children: A Mixed Method Study, International Journal of Indian Psychology, Volume 3, Issue 4, No. 57, ISSN 2348-5396 (e), ISSN: 2349-3429 (p), DIP: 18.01.027/20160304, ISBN: 978-1365-23993-9 